\title{
APLICAÇÃO DO DESIGN SOCIAL EM CONTEXTOS DE REGENERAÇÃO URBANA: ESTUDO DE CASO NO BAIRRO SERRINHA, EM FORTALEZA
}

Filipe Garcia Macambira

Universidade Federal do Ceará

f.macambira@yahoo.com.br

Anna Lúcia dos Santos Vieira e Silva Universidade Federal do Ceará annalucialilu@gmail.com
Emilio Augusto Gomes de Oliveira

Universidade Federal do Ceará

emiliodesign@gmail.com

Carlos Eugenio Moreira de Sousa Universidade Federal do Ceará eugeniomoreira@dau.ufc.br

Adson Pinheiro Queiroz Viana

Universidade Federal do Ceará adson.queiroz12@gmail.com

Resumo: O Design Social tem se apresentado como uma área do conhecimento transversal e interdisciplinar, cujo um dos objetivos é melhorar a integração do homem com seu ambiente. No âmbito social, o design pode atuar como uma ferramenta estratégica que busca soluções colaborativas, direcionadas a novas possibilidades de qualificação e solução de demandas coletivas (MARGOLIN, 2004). Diante disso, este trabalho tem como objetivo avaliar o papel estratégico da atuação do design social como norteador de ações no bairro Serrinha, em Fortaleza, com o intuito de transformar a realidade urbana e social. As diversas camadas de complexidade relacionadas à falta de saneamento básico, alagamentos periódicos e o hábito de descarte de resíduos sólidos em um espaço público deste assentamento informal, denotam as principais problemáticas que definem a situação da comunidade. Por meio de mutirões mensais, fundamentados na pesquisa-ação (TRIPP, 2005; TOLEDO e JACOBI, 2013) um grupo de professores e alunos das áreas de Design, Arquitetura, Urbanismo e Ciências Sociais, somados a outras nove instituições públicas, privadas e não governamentais, se unem à comunidade com o intuito de reverter a situação. A partir do diagnóstico da ausência de vínculo e pertencimento dos moradores do bairro em relação à área estudada, é identificada a necessidade de uma construção de lugar (DUARTE, 2002). Com o esforço coletivo e participativo em descrever e reconhecer as problemáticas locais, dá-se início a um processo de regeneração por meio de uma série de iniciativas táticas (CERTEAU, 2000) responsáveis pela modificação efetiva do uso do espaço e de sua configuração. O design tem um papel fundamental nesse processo, quando o "lixão" se transforma, ao longo de um ano, em uma praça. A aplicação de dispositivos estratégicos como, por exemplo, os calendários de coleta de lixo, elaborados com imagens de moradores, trazem à realidade o intuito de estabelecer um 
vínculo de identidade com o projeto e com o próprio espaço. 0 design também é responsável pelo gerenciamento das ações, informações e conexões entre os diferentes envolvidos. A inclusão da comunidade no processo resolutivo fez com que as soluções para seu próprio benefício repercutissem em autonomia e sustentabilidade urbana. O projeto é concluído com uma proposta executiva que contém soluções de infraestrutura verde, com foco no saneamento e drenagem pluvial, acolhido pela prefeitura municipal para ser executado em 2016. Pode-se concluir que o projeto foi eficiente diante do desenvolvimento e regeneração do espaço, o bem-estar para a comunidade e referências metodológicas para futuras intervenções em contextos sociais similares.

Palavras-chave: Design Social, Regeneração Urbana, Teoria Geral dos Sistemas.

\section{INTRODUÇÃO}

A comunidade Vila Guaribal situada no bairro da Serrinha em Fortaleza encontra-se em área de risco devido à proximidade com a lagoa de Itaperaoba. Durante a quadra chuvosa ocorrem alagamentos que são agravados pela ausência de saneamento básico e pelo acúmulo de resíduos de forma irregular em um dos únicos espaços não construído das proximidades. O local se tornou um lixão a céu aberto, trazendo riscos à saúde dos moradores e dos alunos de uma escola pública infantil, localizada dentro da comunidade e administrada por uma ONG italiana, o Instituto Irmã Giuliana Galli. Preocupados com os riscos e possíveis danos resultantes dessa situação o IIGG e o Movimento Pró-Parque Lagoa da Itaperaoba entram em contato com o programa de extensão "Canto - Escritório Modelo de Arquitetura e Urbanismo da UFC" a fim de conseguir ajuda especializada para a resolução desses problemas e para a transformação dessa área livre em um espaço publico que pudesse ser usufruído pela comunidade. No intuito de unir forças e conhecimentos com profissionais e estudantes de outras áreas, o Canto entrou em contato com o projeto de extensão "Varal - Laboratório de Iniciativas em Design Social", e posteriormente, com outros parceiros, como, a Universidade Estadual do Ceará, organizações não governamentais, órgãos públicos e privados, técnicos especialistas, a sociedade civil organizada e os próprios moradores, criando, dessa maneira, um ambiente de trabalho multidisciplinar e horizontal onde todos os parceiros têm grande influência sobre as decisões e rumos tomados no decorrer do projeto.

Analisando sistematicamente a localidade viu-se a necessidade de estudar as relações entre esse espaço colateral e a cidade como um todo. Notou-se que o local se encontrava desconectado do sistema geral e era inviável adotar métodos tradicionais de projeto, visto que para a realização dessa mudança é necessária não apenas a ajuda dos órgãos públicos mais também da conscientização e desenvolvimento do sentido de pertencimento dos moradores. A partir disso surge o projeto de extensão "Praça Ecológica Vila Guaribal" que propõe a melhoria da situação daquela comunidade através da transformação do lixão existente em uma praça sustentável.

O trabalho irá tratar as formas e estratégias usadas até o momento para a organização das informações complexas e a realização do projeto baseando-se nas 
análises e pesquisas feitas no local e relacionando-as com a Teoria Geral dos Sistemas.

\section{REFERÊNCIAIS PARA ANÁLISE}

\subsection{Fundamentos projetuais}

Diante de caso tão complexo, recorremos a um estudo ontológico por seu enfoque na busca do geral e do completo (VIEIRA, 2008a). Uma Ontologia Cientifica que nos auxiliou na compreensão, de forma ampla, das inter-relações e integrações dos fenômenos observados a Teoria Geral dos Sistemas (TGS), com base nos estudos de Bunge (1977). A TGS em sua proposição de explicar a realidade, nos fala que tudo pode ser encarado como um sistema e todo sistema possui diversos parâmetros, podendo ser eles de natureza fundamental ou evolutiva. Os evolutivos são aqueles que surgem ao longo da vida de um sistema e podem variar com o passar do tempo, podendo estar ou não presentes em determinada época. Já os fundamentais, seriam aqueles que existem independentemente dos processos evolutivos. (VIEIRA, 2008a). Além disso, sistemas abertos, como é o caso da localidade estudada, possuem diversas funções inerentes, como: ingestão, processamento, reação ao ambiente, suprimento das partes, regeneração das partes e organização.

Para fins práticos, iremos nos valer da explanação de dois conceitos, sendo o primeiro de um parâmetro evolutivo e o segundo uma função do sistema aberto. A Organização é um dos sete parâmetros evolutivos citados por Vieira (2008) e ela se apropria de outros dois parâmetros de mesma natureza, a Conectividade, que diz respeito à capacidade de obter conexões entre outros elementos, e a Integralidade, que tem relação com a força entre essas conexões. De acordo com Vieira (2008a),

[...] um sistema será dito organizado quando for composto por subsistemas conectados por relações efetivas [...] com graus variados de importância tanto dos subsistemas quanto das conexões, gerando uma totalidade dotada de propriedades irredutíveis aos subsistemas ou elementos. (idem, p. 43)

Logo, temos a organização ligada diretamente a um caráter orgânico, o que Ihe da um caráter de equilíbrio entre a rigidez total de um padrão e uma flexibilidade amorfa. Como sistema aberto, nossa localidade tem uma função de reação ao ambiente. Onde, ambiente é o sistema envoltório com o qual ela troca energia, matéria e informação na busca pela permanência. Um sistema ao reagir com o ambiente tende a adaptar-se, mudando seus materiais, recursos e produtos, ou seja, ele se reorganiza em um novo sistema que tenda a permanência.

Para mais, também abordamos os fixos e fluxos, de Fabio Duarte (2002), entendendo que toda localidade é uma porção do espaço significada e que a ela são atribuídos valores que refletem a cultura de uma população. De mesmo modo, entendemos a fotografia como estratégia de compreensão e modificação do olhar dos habitantes estudados (GURAN, 2012).

\subsection{Evolução do projeto}

Com o apoio de todos os colaboradores foi desenvolvida uma estratégia para 
que o projeto fosse cíclico e não tivesse interrupções. Decidiu-se que a cada mês ocorreria uma reunião geral com todos os envolvidos no terreno onde se pretende construir a praça. Tais reuniões foram chamadas de mutirões, pois possuiriam a característica da ocorrência contínua de trabalhos, fossem eles de pesquisa, amostragem de resultados ou atividades com a população.

A falta de identificação daquele espaço como um lugar comum a todos, ou seja, ausência de vínculo da comunidade com aquele espaço foi um dos primeiros obstáculos para o projeto. Para os moradores aquele local era nada mais que um lixão, um terreno sem significado. Segundo Cardoso(2012), o olhar é uma construção social e cultural, circunscrito pela especificidade histórica do seu contexto. Logo, foram planejadas ações que pudessem modificar esse olhar dos moradores, como a entrega de calendários, a realização de mudanças físicas no local e a apresentação das propostas para o terreno. Com o passar dos mutirões a população foi mudando seu modo de perceber aquele local. Em um sistema complexo como o abordado, tais tentativas de mudar o olhar da comunidade sobre o terreno podem ser vistas como uma alteração no ambiente geral, e podem gerar reações de reorganização do sistema cujas proporções são imprevisíveis.

\section{MÉTODOS E MATERIAIS}

\subsection{Métodos}

A partir de uma pesquisa de caráter empírico e realizada na comunidade Guaribal nos mutirões de atividades mensais, foram coletados diversos dados por meio de análises psicossociais (através de abordagem com os moradores em reuniões mensais), conhecendo a realidade daquela população e seus principais problemas a fim de tornar o projeto mais assertivo. Foram também aplicados questionários em formato de pesquisa de opinião, tendo como objetivo conhecer os desejos e as preferências para futuras utilizações para a praça e a disponibilidade dos moradores em participar do processo.

Foi usada, como base teórico-metodológica de aprimoramento contínuo das atividades de intervenções participativas, colaborativas e co-criativas, a pesquisa-ação explanada por David Tripp (2005). Além disso, também foram explorados os conceitos de ensino reflexivo de Donald A. Schön (2000), como um processo de "reflexão na ação", e a horizontalidade entre os envolvidos, descrita por Jaques Rancière no artigo “O Espectador Emancipado" (2007).

\subsection{Materiais}

Para o projeto foram desenvolvidos diversos tipos de materiais até o momento, tanto do âmbito do design gráfico como do design de produto, todos visando uma a maior eficiência no nível de comunicação com os moradores e os demais envolvidos. Entretanto, tomaremos dois para a análise, por sua maior relevância no processo sistêmico aqui analisado: os calendários mensais e as apresentações de projeto.

\subsubsection{Calendários mensais}

Como ideia para incentivar um descarte consciente do lixo e atrair a atenção dos moradores para as ações que estavam sendo desenvolvidas mensalmente (os 
mutirões) foram desenvolvidos calendários mensais, que eram impressos e distribuídos de porta-a-porta. Estes são peças gráficas que marcam os dias da coleta de lixo durante o mês que se inicia e trazem como pano de fundo uma fotografia tirada durante a ação do mês anterior, como registro da participação da comunidade.

\subsubsection{Apresentação de projetos}

Paralelamente aos estudos e pesquisas e apoiados nas mesmas, os estudantes e professores envolvidos com o Canto e o Varal desenvolveram propostas e projetos de transformação do local, passando por soluções paisagísticas, de drenagem, design de mobiliários, etc. A apresentação foi feita em diversos meios, tendo sido elaborados desde desenhos técnicos ate fotomontagens simulando as intervenções em cima de fotografias do espaço, passando também pela construção de maquetes físicas. Todo esse material era apresentado nos mutirões, propiciando um ambiente de interação entre comunidade e projetistas. Após cada encontro, novos dados eram recolhidos com o intuito de embasar a evolução dos projetos e validar as soluções propostas.

\section{RESULTADOS E DISCUSSÕES}

Após seis meses de constantes visitas e intervenções, o terreno foi limpo e esta sendo utilizado pela comunidade. A limpeza é mantida por imposição dos moradores das bordas do terreno que não permitem mais que o lixo seja jogado ali. Também nasceu um campinho de futebol, idealizado pelos próprios moradores para impedir o descarte de resíduos no local. O lixo antes acumulado no terreno, hoje é colocado em sacos plásticos na frente das casas nos dias de coleta marcados no calendário. Como resultado, também obtivemos o crescimento do número de órgãos e entidades apoiadores do projeto, cujos olhares finalmente se voltaram para aquela área ambientalmente frágil. De uma pequena equipe de três professores e cinco bolsistas, o projeto se desenvolveu e chegou a abranger uma equipe formada por vinte voluntários, dentre eles estavam moradores do bairro, funcionários do IIGG e alunos de diversos cursos da UFC e da UECE.

A abordagem metodológica sofreu alterações durante o percurso do projeto devido as necessidades que se modificavam a cada nova influencia dos apoiadores e das demandas. Diante disso, pode-se afirmar que os métodos se tornam produtos das articulações que o designer opera entre os seus conhecimentos técnicos, suas vivências cotidianas e as dinâmicas empreendidas nos espaços urbanos e sociais trabalhados, com as especificidades culturais e comunitárias.

Entender que cada sistema é influenciado por diversos fatores é essencial no momento de gerar alguma solução viável a ser aplicada num contexto real. Fazer uso desses fatores a seu favor é qualidade indispensável na criação de um bom projeto, tendo em vista que o enfoque sistêmico tem por objetivo realizar não somente a tarefa pretendida, mas de realizá-la com o máximo de eficiência.

Podemos, então, tomar essa mudança de modo de pensar e agir da comunidade como uma mudança de olhar. Tomando a comunidade como um sistema aberto, podemos dizer que a limpeza do terreno foi resultado de uma perturbação do ambiente que obrigou os moradores a realizar uma reorganização das conexões internas (modos de pensar, agir e comunicar) devido a estímulos de fatores externos, 
o que gerou novos modos de utilização do local e trouxe consigo uma nova possibilidade de permanência sistêmica da comunidade. Mesmo essa permanência não sendo absoluta, esse processo evolutivo é um sinal de que sistemas como o analisado podem passar por rearranjos que os proporcionem maiores condições de permanência local e que, aos poucos, eles se solidifiquem no tempo.

No ambiente também ocorreram modificações, como um campinho de futebol e um parquinho para as crianças da comunidade. Uma vez que no decorrer do processo surgiram novos subsistemas com interesses em estabelecer conexões com a localidade estudada, o projeto começou a ganhar força, reconhecimento local e investimentos financeiros, o que facilitou a realização das ações e a descoberta de novas demandas a serem analisadas e supridas.

\section{CONCLUSÃO}

Entendendo esse caso de uma forma sistêmica, chega-se a conclusão de que o papel do projetista em uma situação como a descrita não é o da criação de uma resposta "certa", mas sim de interfaces entre os sistemas humanos e sua localidade, na intenção de qualificar os conhecimentos sobre a realidade e mostrar possíveis reorganizações das relações no intuito de possibilitar uma maior permanência.

Projetistas e comunidade devem trabalhar em conjunto na elaboração de respostas a realidade tal qual ela é: sistêmica, complexa e legaliforme (VIEIRA, 2008). A horizontalidade quando adotada em tais contextos propicia um aumento no número de conexões estabelecidas, possibilitando um aumento da complexidade e, por consequência, convergindo para a permanência de todos os envolvidos.

Com a construção da "Praça Ecológica Vila Guaribal" em andamento, as conclusões apresentadas também estão em processo, desconfigurando-as, assim, como limites para essa discussão. Muito longe disso, elas ainda são reflexões sobre o que ocorreu até o momento e servem para avaliarmos tal metodologia que não faz uso de fórmulas, mas antes depende de uma cadeia de elaboração de conhecimentos.

\section{REFERÊNCIAS}

BUCKLEY, WALTER, A Sociologia e a Moderna Teoria dos Sistemas. São Paulo, Editora Cultrix, Editora da Universidade de São Paulo, 1971. 307 p.

CARDOSO, Rafael. Design para um mundo complexo. Cosac Naify, 2012.

CHIAVENATO, Idalberto. Introdução à Teoria Geral da Administração. 4a Edição, Ed. Makron Books.

DUARTE, Fábio. Crise das Matrizes Espaciais: arquitetura, cidades, geopolítica e tecnocultura. São Paulo: Perspectiva, 2002.

GURAN, Milton. Documentação Fotográfica e Pesquisa Científica: Notas e Reflexões. Prêmio Funart Marc Ferrez de Fotografia, 2012.

RANCIÈRE, Jacques. O Espectador Emancipado. Trad. de Daniele Avila - Questão de Crítica, 2008. Disponível em <http://www.questaodecritica.com.br/2008/05/oespectador-emancipado>. Acesso em 29 abril de 2013. 
REZENDE, Denis Alcies; ABREU, Aline França de. Tecnologia da Informação Aplicada a Sistemas de Informação Empresariais. 3a Edição, Editora Atlas.

SCHON, Donald A. Educando o profissional Reflexivo. Um novo design para o ensino e aprendizagem. Porto Alegre: Artmed, 2000.

TONET, Fernando. Reconfigurações do constitucionalismo: Evolução e modelos constitucionais sistêmicos na pós-modernidade. Editora Lumen Juris.Rio de Janeiro 2013.

TRIPP, David. Pesquisa Ação: uma Introdução Metodológica. Trad. Lélio Lourenço de Oliveira. Educação e Pesquisa, São Paulo, v. 31, n. 3, p. 443-466, set./dez. 2005.

VIEIRA, Jorge de Albuquerque. Ontologia Sistêmica e Complexidade. Formas de conhecimento e arte: arte e ciência uma visão a partir da complexidade. Fortaleza: Expressão Gráfica e Editora, 2008a. 108p. 